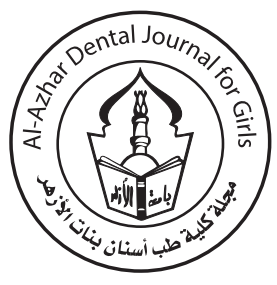

\title{
Effect of Using Boswellia Sacra Extract as Final Irrigant on Removal of Smear Layer
}

\author{
Nehad A. Ahmad ${ }^{1 *}$, Hemat M. Elsheikh², Maha A. Elhousiny ${ }^{2}$
}

Codex : 07/21.01

azhardentj@azhar.edu.eg

http://adjg.journals.ekb.eg

DOI: $10.21608 /$ adjg.2021.39274.1285

Restorative Dentistry

(Removable Prosthodontics, Fixed

Prosthodontics, Endodontics, Dental Biomaterials, Operative Dentistry)

\section{KEYWORDS}

Boswellia sacra,

Smear layer,

Irrigant.

\begin{abstract}
Purpose: To evaluate the impact of $10 \%$ Boswellia sacra water extract (B. sacra) as a final irrigant on smear layer removal consequent to primary irrigation with $2.6 \%$ sodium hypochlorite $(\mathrm{NaOCl})$. Material and Methods: Thirty-six palatal \&distal roots from extracted maxillary \& mandibular molars have being instrumented and categorized into 3 experimental groups depending on the final irrigant used: (12 samples each), Group I: irrigated with $10 \%$ B. sacra extract. Group II: irrigated with 17\% EDTA. Group III: control group irrigated with sterile saline. Irrigation was performed with $5 \mathrm{ml}$ of test substances for 1 minute. Scanning electron microscopic analysis was performed to assess smear layer removal on the coronal, middle, and apical portion for each root canal. Results: no statistically significant difference between using $10 \%$ B. sacra extract \& $17 \%$ EDTA for smear layer removal at the entire root canal levels $(\mathrm{P}=0.000)$. However, there was statistically significant difference between tested irrigant (10\% B sacra extract \& 17\% EDTA) compared to control group. Comparison of the capability to remove smear layer among different root canal levels for each group showed a significant difference in smear layer removal on coronal and apical part for all assessed groups. Conclusion: The current in-vitro study demonstrated that $10 \%$ B. sacra water extract have a chelating potential similar to that of EDTA $17 \%$. Boswellia sacra as natural product is a promising chelating agent.
\end{abstract}

\section{INTRODUCTION}

Success of endodontic treatment depends on thorough debridement of root canal system. All current instrumentation techniques produce dentin chips by action of endodontic instrument which added to remnants of organic material creating a smear layer on the walls of

1. Lecturer of Oral Biology, Faculty of Dental Medicine for Girls, Al-Azhar University, Cairo, Egypt.

2. Lecturer of Endodontics, Faculty of Dental Medicine for Girls, Al-Azhar University, Cairo, Egypt.

* Corresponding author email: dr_nh80@yahoo.com 
root canal ${ }^{(1)}$. Although there is debate concerning whether to retain or remove the smear layer, recent meta-analysis and systematic reviews of in vitro studies reported that smear layer removal opens the dentinal tubules, facilitates irrigants penetration into the tubules, and improves the adaptation of obturation materials to root canal walls that provide fluid-tight seal of the obturated root canal system ${ }^{(2-5)}$.

Irrigation can improve the smear layer removal in combination with mechanical root canal instrumentation ${ }^{(6)}$. Agents used for smear layer removal should eradicate both inorganic and organic materials from all surfaces of root canal without damaging erosive effects on dentin ${ }^{(7)}$. The most popular irrigating solution is sodium hypochlorite $(\mathrm{NaOCl})$, it had been used as the main irrigant as early as 1920 . Aqueous $\mathrm{NaOCl}$ has antibacterial and tissue dissolution capacity, but it has weaknesses as it dissolves only organic material without dissolving inorganic dentin particles, thus it cannot remove the smear layer ${ }^{(8-10)}$.

Demineralizing agents used for removal of the inorganic part of the smear layer such as ethylenediaminetetraacetic acid (EDTA) was recommended to be used as adjuvant in root canal therapy alternatingly with $\mathrm{NaOCl}$ solutions to remove the smear layer ${ }^{(1,6)}$. However, there is worry that this combined irrigation procedure causes negative erosion of the dentin wall ${ }^{(7)}$. It was reported that irrigation using 10mLof $17 \%$ EDTA for just 1 minute was effective in removing smear layer, however a 10 -minute application can cause excessive peritubular and intertubular dentinal erosion ${ }^{(11)}$. Moreover, the chelating effect of EDTA was nearly negligible in the apical third of the root canals ${ }^{(12)}$. EDTA has no or little antibacterial effect since it is neither bactericidal nor bacteriostatic and kills bacteria by starvation through chelating metallic ions important for bacterial growth ${ }^{(13,14)}$.

Therefore, there is need to identify an effective agent for smear layer removal without harmful effect, thus natural irrigants have been introduced to minimize the harmful effect of EDTA on dentin and periapical tissues.

Boswellia sacra Flueck (Burseraceae) oleo gum resin commonly known as frankincense is one of the most commonly used household medicine and marketed throughout the world ${ }^{(15)}$. In Arabic, it is known as "Luban" and masticated for its quintessence in Arab-African and Middle East countries (16). The color of dried oleo gum resin has creamy to light brown color, with a special characteristic odor $^{(17)}$. Frankincense resin is traditionally used in different Asian countries to cure urinary and bronchial infections ${ }^{(17)}$. Also, B. sacra gum resin is recognized to help in curing of wounds, sores, ulcers, carbuncles, and hemorrhoids. The essential oils of the frankincense are believed to possess antiseptic, carminative, astringent, diuretic, digestive, uterine, vulnerary, and sedative therapeutic properties ${ }^{(18)}$. The frankincense water extract also used by tradition to relieve cough, throat, mouth, gum, menstrual pain and the treatment of liver and stomach problems in Arab-African and Middle Eastern nations ${ }^{(19)}$.

Although this gum resin is generally used as house-hold medicine, there is no scientific report mentioned its dental benefits. This study was undertaken to determine effect of water extract of $10 \% \mathrm{~B}$. sacra on smear layer removal from coronal, middle, and apical parts of root canal system using scanning electron microscope. Null hypothesis of this study that there is no difference between B. sacra water extract \& $17 \%$ EDTA in capability to remove smear layer in all root canal levels.

\section{MATERIAL AND METHODS}

\section{Teeth selection:}

Thirty-six extracted mandibular and maxillary human molars were picked from a random collection and assessed for absence of cracks, root caries, or previous root canal treatment. Ethical approval in the use of extracted human teeth was acquired in 
accordance with guidelines from Research ethics committee (REC) of Faculty of Dental Medicine, Al-Azhar University. Soft debris was removed using hand curettes. Molars Crown was removed using a carborundum disc at the cementoenamel junction under water cooling. Distal roots of mandibular molars and palatal roots of the maxillary molars were trimmed coronally using diamond disc to uniform length of $16 \mathrm{~mm}$ and stored in saline to prevent dehydration until use.

\section{Preparation of B. sacra extract:}

Boswellia sacra $10 \%$ water extract was prepared by dissolving $1000 \mathrm{mg}$ B. sacra oleo gum resin powder in $100 \mathrm{ml}$ distilled water at $50^{\circ} \mathrm{C}$ using a magnetic stirrer plate in closed jar for 2 hours until homogenous. The solution was filtered using cellulose filter paper thus clear purified solution of $10 \mathrm{mg} / \mathrm{ml}$ concentration was obtained. The acidity value of the solution was measured using $\mathrm{pH}$ meter (4.4) and then the prepared solution was kept in a closed container.

\section{Specimens' preparation:}

k-file \# 10 was used to determine the working length which adjusted to be $1 \mathrm{~mm}$ shorter from the apex. Root canals preparation was performed using Universal Protaper rotary files following manufacturer's recommendation. After each change of instrument, canals were irrigated with $2 \mathrm{ml}$ of 2.6 $\mathrm{NaOCl}$ using 27-gauge side vented needles. Final$1 y$, root canals were rinsed with distilled water and dried using paper points.

Thirty-six specimens were distributed into 3 groups according to the final irrigant used: (12 roots each), Group I: irrigated with $10 \%$ B. sacra water extract. Group II: irrigated with 17\% EDTA. Group III (control group): irrigated with sterile saline. The final irrigation protocol was standardized for all specimens by using $5 \mathrm{ml}$ of irrigant for 1 minute, then $10 \mathrm{ml}$ of distilled water to eliminate the residue.

\section{Scanning electron microscopic (SEM) evaluation:}

The specimens were split vertically into two halves, guided grooves were made longitudinally along mesial and distal surface of each specimen using diamond disc. Finally, the root was split into parts with chisel and mallet to reveal the root canal wall. Hemisected specimens were mounted on metallic stump using conductive glue and examined at coronal, middle, and apical root levels using SEM. Two digital photomicrograph at magnification $\mathrm{X}$ $2000 \&$ X1000 were taken at the center of each third.

The scoring procedure was performed blindly by two endodontists who were not identical with the operator who had prepared the canals and had no knowledge of the study. Allocating scores to the degree of smear layer removal may be biased by lack of objectivity. In order to reduce this, we acquired two images at di-erent magnifications to permit a more wide-ranging analysis of each specimen in each portion of its root canal system. Smear layer evaluation was done by using a five-point scoring system with Hulsmann score (20) Score1:no smear layer and dentinal tubules widely opened. Score2: a little quantity of smear layer and some dentinal tubules open. Score3: homogeneous smear layer coating the root canal while just a few dentinal tubules open. Score4: entire root canal coated by a homogenous smear layer and no open dentinal tubules. Score5: intense, non-homogeneous smear layer coating the root canal surface completely.

\section{Statistical analysis:}

Data have been collected and statistically evaluated, for multiple independent parametric variables Kruskal Wallis test was used to determine the significance in the difference between multiple independent parametric variables. While Post-hoc-Tukey test used when Kruskal Wallis test was significant to show between which groups the significant difference present. The significance level was determined at $\mathrm{p}$-value $<0.05$. 


\section{RESULTS}

Median, minimum, and maximum of all tested groups were represented in table (1). Comparison of smear layer scores between tested irrigants at all root levels using Kruskal Wallis test showed that there was a significant difference between the groups at all root canal level $(\mathrm{p}=0.001)$. Post hoc test revealed that, there was a statistically significant difference between tested irrigant (10\% B .sacra extract \& 17\% EDTA) compared to the control group. However, there was no significant difference in score for smear layer removal produced by $10 \%$ B.sacra extract\& 17\% EDTA. So, specimens irrigated with $10 \%$ B.sacra extract\& 17\%EDTA showed more efficacy in the removal of the smear layer than the saline (control) group.

Table (1): Descriptive analysis of smear layer score at coronal, middle \& apical root levels of all the studied groups.

\begin{tabular}{|c|c|c|c|c|c|c|c|c|c|c|}
\hline \multirow{2}{*}{$\begin{array}{c}\text { Root } \\
\text { level }\end{array}$} & \multicolumn{3}{|c|}{$\begin{array}{c}\text { Group I } \\
\text { B.Sacra 10\% }\end{array}$} & \multicolumn{3}{c|}{$\begin{array}{c}\text { Group II } \\
\text { EDTA17\% }\end{array}$} & \multicolumn{3}{c|}{ Group III } \\
\cline { 2 - 12 } & Min & Max & Median & Min & Max & Median & Min & Max & Median \\
\hline Coronal & 1.00 & 3.00 & $2.00^{\mathrm{a}}$ & 1.00 & 3.00 & $2.00^{\mathrm{a}}$ & 3.00 & 5.00 & $4.00^{\mathrm{b}}$ & $0.001^{*}$ \\
\hline Middle & 1.00 & 4.00 & $3.00^{\mathrm{a}}$ & 2.00 & 3.00 & $3.00^{\mathrm{a}}$ & 3.00 & 5.00 & $4.50^{\mathrm{b}}$ & $0.001^{*}$ \\
\hline Apical & 2.00 & 5.00 & $3.50^{\mathrm{a}}$ & 3.00 & 4.00 & $3.00^{\mathrm{a}}$ & 4.00 & 5.00 & $5.00^{\mathrm{b}}$ & $0.001^{*}$ \\
\hline Total & 1.00 & 5.00 & $3.00^{\mathrm{a}}$ & 1.00 & 4.00 & $3.00^{\mathrm{a}}$ & 3.00 & 5.00 & $5.00^{\mathrm{b}}$ & $0.001^{*}$ \\
\hline
\end{tabular}

* Significant at $P<0.05$.

Another comparison of smear layer score among each root level for different groups showed a significant difference in smear layer removal at coronal and apical root canal for all examined groups as shown in Fig (1) \& (2).For groups (I, II\& III) P-value were $(0.005,0.001 \& 0.025)$ respectively. However, at the middle level of root canal, there was no significant difference when compared with apical and coronal parts regardless of the type of tested irrigant.

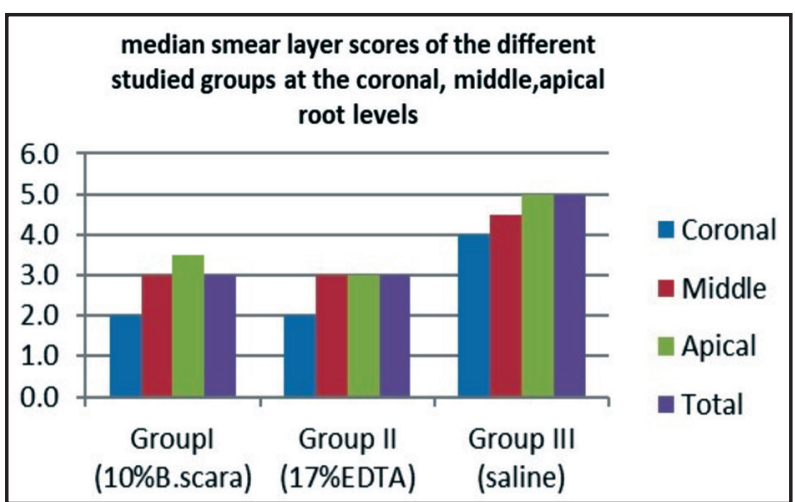

Figure(1) : A bar chart comparing the mean scores of smear layer among $10 \%$ B. sacra, EDTA17\%, and saline groups at the coronal, middle \& apical levels. 


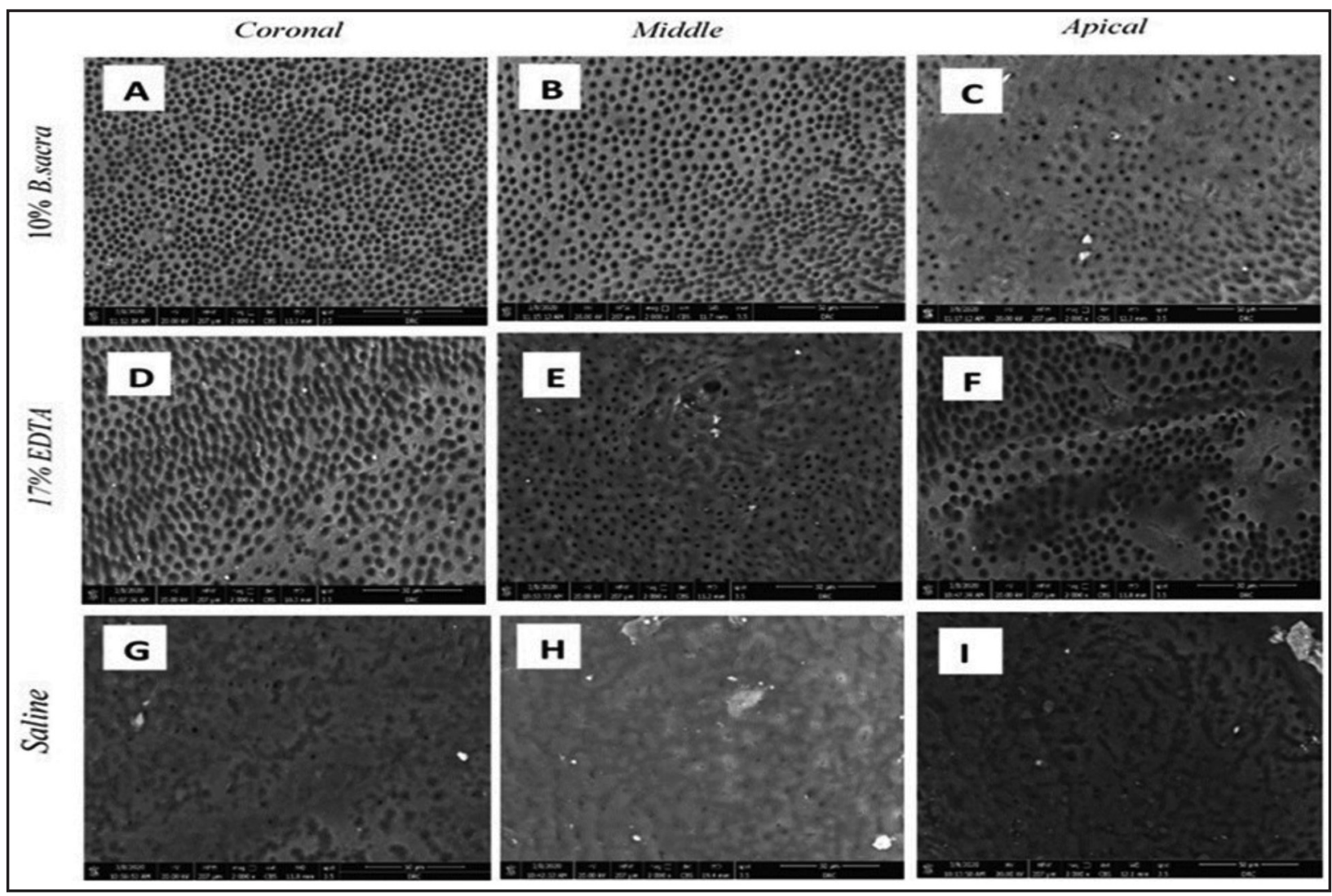

Figure (2): Representative SEM of all groups \& all canal thirds A,B\&C:10\%B.sacra extract at the coronal, middle \& apical third. D,E\&F:EDTA17\% at the coronal, middle\& apical thirds. G,H\&I: Saline (control) at coronal, middle\& apical third.(SEM; original magnification $\times 2000$ )

\section{DISCUSSION}

Irrigation has an important role in root canal therapy during and after preparation, the irrigants accelerate removal tissue remnants, microbes, and dentin chips from the root canal system. Smear layer created during mechanical preparation of root canals that covers the dentinal walls, it contains organic and inorganic material ${ }^{(1)}$, bacteria, and bacterial byproducts and protects the bacteria in the dentinal tubules ${ }^{(21)}$. Moreover, it prevents the penetration of intracanal disinfectants ${ }^{(22)}$ and root canal sealers into dentinal tubules ${ }^{(23)}$. It was reported that lack of adherence between the filling material and the smear layer covering root canal walls that can affect the apical seal which subsequently resulted in apical leakage, which favoring bacterial survival and multiplication that were not removed during the chemomechanical preparation ${ }^{(4,24)}$.

The most prevalent protocol used for smear layer removal is the alternate use of $\mathrm{NaOCl}$ and EDTA but causes a reduction in strength of dentin ${ }^{(7)}$. Because of its harmful effect, the quest for more dentin friendly and biocompatible irrigants that can overcome the restrictions of those chemical antimicrobial irrigants is still on the increase. So, this study aimed to assess the impact of Boswellia sacra water extract on the removal of smear layer.

As mentioned previously, B.sacra is resin gum, which is known as incense or frankincense, is mostly used as house-hold medicine in different parts of the world. The dry oleo gum resin has a 
creamy to whitish brown color with a distinguishing odor $^{(17)}$. It is habitually used in several Asian nations to cure urinary and bronchial diseases. In China, the gum resin used to mitigate gum, mouth, and throat complaints, and in India also used as a regenerating medicine ${ }^{(15,18)}$.

Endodontic irrigants should have essential properties like biocompatibility, bactericidal action, anti-inflammatory, and capability to remove smear layer from the root canal walls ${ }^{(25)}$. B. sacra are biocompatible and have anti-inflammatory properties science it traditionally used to help in the recovery of ulcers, abrasions, carbuncles, sores, hemorrhoids, and inflammation. It was also reported that B. sacra oleo resin gum water extract improved the healing of acetic acid-induced chronic gastric ulcers in rats ${ }^{(17,19)}$.

The anti-bacterial action is a principal requirement for efficient intracanal irrigants. The essential oils of B. sacra oleo gum resin are believed to possess therapeutic and antiseptic properties ${ }^{(18)}$. Gas chromatography-mass spectroscopy (GC-MS) laboratory analysis of the B. sacra water extract showed presence of different chemical elements. Some of the major ingredients of all the compounds identified and the most redundant were 3-cyclohexen1-ol $(21.33 \%)$, octanoic acid (18.91\%), menthol $(10.81 \%)$, thymol $(6.14 \%)$, and carvacrol ${ }^{(17)}$. Menthol is commonly used in dental care products as a topical antibacterial agent and was reported to be effective against various types of streptococci and lactobacilli ${ }^{(26)}$.Cyclohexen-1-olwhich is derivative of limonene reported to be effective antimicrobial agent ${ }^{(27)}$. Thymol is phenol derivative has strong antiseptic properties and demonstrates invitro antibacterial effect against the tested strains of P. aeruginosa, E. coli ,B. cereus, and Staphylococcus aureus ${ }^{(28)}$. Octanoic acid (Caprylic Acid) is a type of beneficial saturated medium- chain fatty acid with anti-inflammatory, antibacterial, antifungal and antiviral properties ${ }^{(29,30)}$. Carvacrol was reported to has antimicrobial activity against different 25 periodontopathic bacteria and strains, and fungi such as R. solani, F. moniliforme, P. capsici and S.clerotirum ${ }^{(31)}$.Thus B. sacra gum oleo resin was selected to be tested as endodontic irrigant for smear layer removal.

Traditionally the commonest method for the preparation of dried out B. sacra oleo gum resin water extract requires covering the resin in a wire mesh or a muslin cloth and submerging it in boiled water for $15-30 \mathrm{~min}$. Another procedure used is to soak frankincense powder overnight in water and after purification used for oral administration ${ }^{(17,32,33)}$. In this study, $10 \%$ water extract was obtained by dissolving $1000 \mathrm{mg}$ powder in $100 \mathrm{ml}$ distilled water in a closed jar at $50^{\circ} \mathrm{C}$ using a magnetic stirrer plate for 2 hours until become a homogenous solution ${ }^{(34)}$. It then filtered using cellulose filter paper to obtain a purified $10 \mathrm{mg} / \mathrm{ml}$ clear solution. This method was used to obtain accurate concentration, fresh solutions to preserve the essential oils. Essential oils are known as volatile oils, easily evaporated at normal temperatures ${ }^{(35)}$.

This current study aimed to compare the impact of both $10 \%$ B sacra water extract and EDTA $17 \%$ as final irrigant on removal of smear layer. The irrigation protocol used for the tested solutions was using $5 \mathrm{ml}$ for 1 minute ${ }^{(11)}$. Studies had reported that using EDTA irrigant for more than a minute resulted in erosion of dentinal tubules, which consequently reduced dentin microhardness ${ }^{(36,37)}$.

The results of this study revealed that $10 \% \mathrm{~B}$. sacra water extract provides results which were comparable to that reported by EDTA 17\% solution particularly in both coronal and middle thirds of root canal, but EDTA (Group II) results in apical third were better than B. sacra water extract group (Group I) but difference was not significant.

Regarding the results reported in Group, I using gum extract, the ability B. sacra water extract to remove the smear layer could be attributed due to 
the presence of constituents reported by GC-MS analysis of B. sacra like Octanoic acid (Caprylic Acid), methanol, and carvacol extract which was reported to have a chelating effect ${ }^{(17)}$. The caprylic acid was reported to be one of component suspected to be effective in smear layer removal using German Chamomile (Marticaria Recutita) water extract ${ }^{(38,39)}$. Methanol which is one of major chemical ingredients present in the water extract of Boswellia sacra was reported to had a chelating effect ${ }^{(40)}$. Also, studies evaluated the chelating effect reported that carvacrol indicating the occurrence of a chelating effect ${ }^{(41)}$.

With regarding to ability of smear layer removal at different level of the root canal, current results of both tested solutions showed maximum smear layer removal at both coronal and middle thirds and the least cleaning efficacy was at apical third and the difference was statistically significant. This result agrees with different studies which evaluated effect of EDTA on smear layer removal ${ }^{(42-46)}$. This result may be due to stagnation plane of the residual fluid of irrigant at apical third that attributed to irrigation technique $^{(42)}$.

It was notified that dentine in the apical third of root canal is sclerosed and thus chelating agents may not have such a vigorous impact on this third as compared to effect on coronal or middle thirds of root canal dentine ${ }^{(43)}$.EDTA may also showed lesser amount of decalcification in the apical third of root dentine due to the substance of non-collagenous proteins decreases in this root canal area ${ }^{(44,45)}$.The same concept can be applied to B. sacra extract science it contains chelating agents.

In the present study, the evaluation of smear layer requires high magnification levels that can be achieved only through using scanning electron microscopy (SEM). It has proved to be a serviceable method for the assessment of debris and smear layer, several investigators used (SEM) in evaluating the efficacy of various irrigation protocols in the elimination of smear layer ${ }^{(47,48)}$.

\section{CONCLUSION}

The current in-vitro study demonstrated that $10 \%$ B. sacra water extract had a chelating potentiality comparable to that of EDTA $17 \%$. Boswellia sacra as a natural product is a promising chelating agent. Therefore, the null hypothesis of this study was accepted.

Further studies are needed to assess B. sacra extract regarding its biological, antimicrobial, and chemical properties in order to confirm its benefits as a final root canal irrigant.

\section{REFERENCES}

1. Mohammadi Z, Shalavi S, Yaripour S, Kinoshita JI, Manabe A, Kobayashi M, et al. Smear layer removing ability of root canal irrigation solutions: a review. J Contemp Dent Pract. 2019; 20:395-402

2. Kanaan CG, Pelegrine RA, Da Silveira Bueno CE, Shimabuko DM, Pinto NM, Kato AS. Can irrigant agitation lead to the formation of a smear layer? J Endod .2020; 46:1120-24.

3. Patil PH, Gulve MN, Kolhe SJ ,Samuel RM, Aher GB .Efficacy of new irrigating solution on smearlayer removal in apical third of the root canal.A scanning electron microscope study. J Conserv Dent .2018; 21:190-3.

4. Shahravan A, Haghdoost AA, Adl A, Rahimi H, Shadifar F. Effect of smear layer on sealing ability of canal obturation: a systematic review and meta-analysis. J Endod 2007; 33:96-105.

5. Alamoudi RA. The smear layer in endodontic: To keep or remove-an updated overview. Saudi Endod J. 2019 ;9 :71-2.

6. Arias-Moliz MT, Ruiz-Linares M, Ferrer-Luque CM. Irrigating solutions in root canal treatment. Endod Practice Today J. 2019 ;13:389-98.

7. Da Silva Beraldo ÂJ, Silva RV, Da Gama Antunes AN, Silveira FF, Nunes E. Scanning electron microscopic evaluation of smear layer removal using isolated or interweaving EDTA with sodium hypochlorite. Iran Endod J. 2017;12:55-59.

8. Gonçalves LS, Rodrigues RC, Andrade Junior CV, Soares RG, Vettore MV. The effect of sodium hypochlorite and chlorhexidine as irrigant solutions for root canal disinfection: A systematic review of clinical trials. J Endod. 2016; 42:527-32. 
9. Estrela C, Estrela CR, Barbin EL, Spanó JC, Marchesan MA, Pécora JD. Mechanism of action of sodium hypochlorite. Braz Dent J. 2002; 13:113-7.

10. Ayad MF. Effects of rotary instrumentation and different etchantson removal of smear layer on human dentin. J Prosth Dent. 2001;85: 67-72.

11. Singh S, Singh M, Salgar AR, Chandrahari N, Prathibha N, Koppolu P. Time dependent effect of various irrigants for root canal on smear layer removal. J Pharm Bioallied Sci. 2019;11:51-58.

12. Estrela C, Lopes HP, Elias CN, Leles CR, Pécora JD. Cleanliness of the surface of the root canal by apple vinegar, sodium hypochlorite, chlorhexidine and EDTA. Rev Assoc Paul Cir Dent. 2007; 61: 177-82.

13. Sharaf NF, Alshareef WA. The Comparative evaluation of the post-antimicrobial effect of MTAD and 2\% Chlorhexidine against Enterococcus faecalis of permanent teeth with necrotic pulp. Open Access Maced J Med Sci. $2019 ; 7: 3270-75$.

14. Shabahang S, Torabinejad M. Effect of MTAD on Enterococcus faecalis contaminated root canals of extracted human teeth. J Endod.2003; 29:576-9.

15. Ben-Yehoshua S, Borowitz C, Hanus LO. Spices:Frankincense,myrrh, and balm of gilead: Ancient spices of southern arabia and judea. Horticul Rev.2012; 39:1.

16. Al-Odaib AN, Abu-Amero KK, Ozand PT, Al-Hellani AM. A new era for preventive genetic programs in the Arabian Peninsula. Saudi Med J.2003 ;24:1168-75.

17. Asad M, Alhomoud M. Proulcerogenic effect of water extract of Boswellia sacra oleo gum resin in rats. Pharmaceutical biology. 2016 1;54:225-30

18. Khan AJ. Medicinal properties of frankincense. Int J Nutr Pharmacol Neurol Dis.2012; 2:79-81.

19. Di Stefano V, Schillaci D, Cusimano MG, Rishan M, Rashan L. In vitro antimicrobial activity of frankincense oils from boswellia sacra grown in different locations of the dhofar region (Oman).Antibiotics.2020;9:195-203.

20. Hülsmann M, Rümmelin C, Schäfers F. Root canal cleanliness after preparation with different endodontic handpieces and hand instrument. A comparative SEM investigation.J Endod.1997; 23:301-6.

21. Morago A, Ruiz-Linares M, Ferrer-Luque CM, Baca P, Rodríguez Archilla A, Arias-Moliz MT. Dentine tubule disinfection by different irrigation protocols. Microsc Res Tech. 2019;82:558-63.
22. Buurma HA, Buurma BJ. The effect of smear layer on bacterial penetration through roots obturated using zinc oxide eugenol-based sealer. BMC Oral Health. 2020 ; 20:88-90.

23. Machado R, Garcia LDFR, da Silva Neto UX, Cruz Filho AMD, Vansan LP. Evaluation of 17\% EDTA and $10 \%$ citric acid in smear layer removal and tubular dentin sealer penetration. Microsc Res Tech. 2018; 81:275-82.

24. Ranjitha GR, Mutha SR, Anithakumari R, Vikram R, Kumar N, Shivekshith AK. Comparative evaluation of smear layer removal efficacy of three herbal irrigants in the apical third of the root canal: An in vitro scanning electron microscopic study. J Res Med Sci. 2020; 11:61-63.

25. AgrawalVineet S, Rajesh M, Sonali K, Mukesh P. A contemporary overview of endodontic irrigants-A review. J Dent App. 2014;1:105-5.

26. Shakya VK, Luqman S, Tikku AP, Chandra A, Singh DK. A relative assessment of essential oil of Chrysopogon zizanioides and Matricaria chamomilla along with calcium hydroxide and chlorhexidine gel against Enterococcus faecalis in ex vivo root canal models. J Conserv Dent. 2019; 22:34-39.

27. Dakah A, Maarrouf M. Antileishmanial and antibacterial activity of essential oils of medicinal plant achilleasantolina L. J Bio Sci. 2019; 19: 69-76.

28. Kachur K, Suntres Z. The antibacterial properties of phenolic isomers, carvacrol and thymol. Crit Rev Food Sci Nutr. 2020;60:3042-53.

29. KimSA, Rhee MS. Antibacterial activity of caprylic acid for potential application as an active antiseptic ingredient in consumer antiseptics. Inter JAntimicrob Agents. 2016;6:765-7.

30. Rosenblatt J, Reitzel RA, Raad I. Caprylic acid and glyceryltrinitrate combination for eradication of biofilm. Antimicrob Agents and Chemotherapy.2015;59:1786-8.

31. Andersen A. Final report on the safety assessment of sodium p-chloro-m-cresol, p-chloro-m-cresol, chlorothymol, mixed cresols, m-cresol, o-cresol, p-cresol, isopropyl cresols, thymol, o-cymen-5-ol, and carvacrol. Int J Toxicol. 2006; 25:29-32.

32. Al-Yasiry AR, Kiczorowska B. Frankincense.therapeutic properties. Postepy Hig Med Dosw . 2016 ;70:380-91.

33. Paul M, Brüning G, Bergmann J, Jauch J. A thin layer chromatography method for the identification of three different olibanum resins (Boswellia serrata, Boswellia papyrifera and Boswellia carterii , respectively, Boswellia sacra). Phytochem Anal. 2012;23 :184-9. 
34. Yadav P, Chaudhary S, Saxena RK, Talwar S, Yadav S. Evaluation of Antimicrobial and Antifungal efficacy of Chitosan as endodontic irrigant against Enterococcus Faecalis and Candida Albicans biofilm formed on tooth substrate. J Clin Exp Dent.2017; 9:361-7.

35. Aziz ZA, Ahmad A, Setapar SH, Karakucuk A, Azim MM, Lokhat D. Essential oils: extraction techniques, pharmaceutical and therapeutic potential-a review. Current drug metabol.2018;19:1100-10.

36. Safwat HA, Nour El-deen MM, Bastawy HA. Evaluation of smear layer removal and calcium ions concentration in intraradicular dentin treated with apple vinegar. ADJ -for Girls. 2017; 4:279-87.

37. Ballal NV, Jain H, Rao S, Johnson AD, Baeten J, Wolcott JF. Evaluation of smear off, maleic acid and two EDTA preparations in smear layer removal from root canal dentin. Acta Odontol Scand. 2019;77 :28-32.

38. Sadr Lahijani MS, RaoofKateb HR, Heady R, Yazdani D. The effect of German chamomile (Marti ariarecutita L.) extract and tea tree (Melaleucaalternifolia L.) oil used as irrigants on removal of smear layer: a scanning electron microscopy study. Int Endod J 2016; 39:190-5.

39. Venkateshbabu N, Anand S, Abarajithan M, Sheriff SO, Jacob PS, Sonia N. Natural Therapeutic Options in Endodontics - A Review. The Open Dent J 2016; 10:214-26.

40. Téllez-López MÁ, Mora-Tovar G, Ceniceros-Méndez IM, García-Lujan C, Puente-Valenzuela CO, del Carmen VegaMenchaca M, Serrano-Gallardo LB. Evaluation of the chelating effect of methanolic extract of Coriandrumsativum and its fractions on wistar rats poisoned with lead acetate. Afr J Tradit Complement Altern Med. 2017; 14: 92-102.
41. Ferreira VR, Nelson DL, Saczk AA, da Silva Felix F, Brandão RM, das Graças Cardoso M. Chelating effect of carvacrol and the oregano essential oil. FactaUniversitatis, Series Physics, Chemistry and Technology $49^{\text {th }}$ ISEO. 2018; 4: 99-105.

42. Shirazi MM, Abouali O, Emdad H, Nabavizadeh M, Mirhadi H, Ahmadi G. Numerical and analytical investigation of irrigant penetration into dentinal microtubules. Comput Biol Med. 2017 ;89:1-17.

43. Vasiliadis L, Darling AI, Levers BG. The amount and distribution of sclerotic human root dentin. Arch Oral Biol. 1983; 28:645-49.

44. Antunes PVS, Flamini LES, Chaves JFM, Silva RG, Cruz Filho AMD. Comparative effects of final canal irrigation with chitosan and EDTA. J Appl Oral Sci. 2019;28:20-19.

45. Hulsmann M, Heckendorff M, Lennon A. Chelating agents in root canal treatment: mode of action and indications for their use. Int Endod J. 2003; 36:810-30.

46. Rathakrishnan M, Sukumaran VG, Subbiya A. To evaluate the efficacy of an innovative irrigant on smear layer removal-SEM analysis.JCDR.2016; 10: 104- 6 .

47. Ballal V, Rao S, Al-Haj Husain N, Özcan M. Evaluation of smear layer removal using different irrigation methods in root canals. Eur J Prosthodont Restor Dent. 2019;27 :97-102.

48. Kiran S, Prakash S, Siddharth PR, Saha S, Geojan NE, Ramachandran M. Comparative evaluation of smear layer and debris on the canal walls prepared with a combination of hand and rotary ProTaper technique using scanning electron microscope. J Contemp Dent Pract. 2016 $1 ; 17: 574-81$. 